\title{
STATISTICAL ANALYSIS OF WIND SPEED FOR ELECTRICAL POWER GENERATION IN SOME SELECTED SITES IN NORTHERN NIGERIA
}

\author{
A. Abdulkarim ${ }^{1,}{ }^{*}$, S. M. Abdelkader2, D. J. Morrow ${ }^{3}$, A. J. Falade ${ }^{4}$ and Y. A. Adediran ${ }^{5}$ \\ 1,4,5 DEPARTMENT OF EleCtricAl and ELECTRONICS ENGINEERING, UNIVERSITY OF IlORIN, KWARA STATE, NIGERIA \\ 2DEPARTMENT OF ELECTRICAL ENGINEERING, FACULTY OF ENGINEERING, MANSOURA UNIVERSITY, EGYPT \\ 3SCHOOL OF ELECTRONICS, ELECTRICAL ENGR. AND COMPUTER SCI., QUEEN'S UNIV. BELFAST, UNITED KINGDOM \\ Email addresses:1 abdulkarim.a@unilorin.edu.ng, ${ }^{2}$ sobhy_abdelkader@yahoo.com,32dj.morrow@ee.qub.ac.uk, \\ 4 falade.alaba@yahoo.com, 5 yinusaade2012@gmail.com
}

\begin{abstract}
In this paper, statistical analysis is carried out to determine the accurate frequency distribution that fits wind speed data. The frequency distributions used include Weibull, Rayleigh and Gamma distribution functions. The performances of the probability distributions are based on the error evaluations between the predicted and the theoretical wind power densities of the site. The Results show that Weibull distribution modelled the wind speed better compared to other distribution functions. According to the European Wind Energy Association, most of the sites are suitable for the generation of electrical energy. Also, the results have shown that Jos, Kano and Minna fall in class 4 and therefore suitable for both off grid and grid connected modes. In addition, the effects of $c$ and $k$ parameters on the probability distribution functions have been presented.
\end{abstract}

Keywords: Wind speed - probability - density function - wind energy conversion system- statistical analyses

\section{INTRODUCTION}

In order to predict and model the potential of any site, either historical records of the renewable energy potentials or statistical methods are employed. Site potential analysis is considered the first step in the design of any system of renewable energy sources. In order to use historical records from the site, it is recommended that data for at least 3years and above are used. But for areas with sparse or limited data, a year measurement may be adequate to at least describe the seasonal variability of the wind-speed. Some of the drawbacks of the historical approach include data accuracy, time, technical challenges and expense. These may result in unrealistic or inaccurate predictions. Recently, statistical methods have gained much popularity. Some reasons for this are economy, shorter times and the possibility of predicting the behaviour of the system with less error [1]. Therefore, statistical methods are now employed for the analysis of renewable energy resources. Statistical distributions used for the assessment of the renewable energy potential at a site include Weibull, Gamma, Lognormal, Rayleigh and Pearson type three to mention but few. Much work has been carried out in analysing the renewable energy potential of particular sites. The wind-energy potential of Penjwen region, Iraq has been investigated in [2], the Weibull distribution was found to fit the wind-speed data. Statistical analysis of windspeed data for Malaysia using lognormal and Weibull distributions are given [3]. In addition, Weibull distribution is proposed to fit the wind speed energy potentials of Tehran [4]. Similarly, the Weibull distribution also fit the wind-speed data of Turkey [5]. At some sites, the Weibull is not suitable, and it was found that Burr, lognormal and gamma distributions performed better than Weibull, Rayleigh or Freshet distributions in Pakistan [6]Another application of statistical analysis of wind-energy potentials includes analysis of wind data in India [7].

Previous works in the wind energy potential of some sites in Nigerian have been reported in [8]-[12] However, while these works reported that the wind speed in Nigeria varies from 2 to $9.5 \mathrm{~m} / \mathrm{s}$. The reported figure in the literature could be related to the time, measurement, accuracy of the data used and the method of data analysis. Mean wind speed and power densities of about 30 locations for period of 8 to 30 years were obtained in [8]. Authors in [9] reported the maximum extracted wind power and mean wind speed across the six geopolitical zones in Nigeria. In similar 


\section{Statistical Analysis of Wind Speed For Electrical Power Generation In Some Selected Sites In ... , A. Abdulkarim, et al}

way, authors in [10] have fitted Weibul, normal, gamma, and Raleigh distributions for 8 locations in Nigeria. Wind speed analysis in [11], is based on 2parameter Weibull distribution which may not accurately fit the wind speed data of all the sites. Furthermore in [12] Gumbel and the Weibull probability distributions were used show the economic viability of using wind energy resources at Calabar, Warri and Katsina

In this paper the probability distributions mentioned are employed to fit wind speed data of some selected sites in Northern Nigeria. This is because the design of wind energy conversion systems depends on the correct analysis of the site renewable energy resources [13]. In addition, the statistical judgements are based on the accuracy in fitting the available data at the sites.

\subsection{Determination of the Mean Wind Speed}

Wind speed is the fundamental factors considered in the development of wind energy conversion systems. The judgements begin with the determination of the mean wind speed, which acts as an important parameter in the wind-power generation system. Therefore, the mean wind speeds, for some sites were obtained from data collected over a period of one year. The data involved are sampling of wind speed and solar radiation at 5 minute intervals. The Quarterly samples of the wind speed data used in the analysis are shown in Figures 1 to 4 for January, April, August and December respectively.

The mean wind speed, $v_{m}$ of the site is normally obtained using Equation (1). Using this method may lead to underestimation of the site potential [14]. However, the month-to-month wind-speed variation of a particular site can vary between $-30 \%$ to $+30 \%$ of the annual average [15].

$$
v_{m}=\frac{1}{N} \sum_{i}^{N} v_{i}
$$

where $v_{i}$ is the wind observed, and $N$ is the data point. Regardless of the shape and scale parameters, use of mode or the mean wind speed in the power density equation would always introduce a significant error in the energy estimate. It can alter the result by several folds, therefore making the estimate useless. Therefore, for the assessment of the site power density due to the wind speed, root mean cube (RMC) speed is used. The expression for the RMC speed, $v_{r m c}$ is given in Equation (2). Therefore, in this paper RMC speed is used, and always provides a correct estimate [14].

$$
v_{r m c}=\sqrt[3]{\frac{1}{N} \sum_{i=1}^{N} v_{i}{ }^{3}}
$$

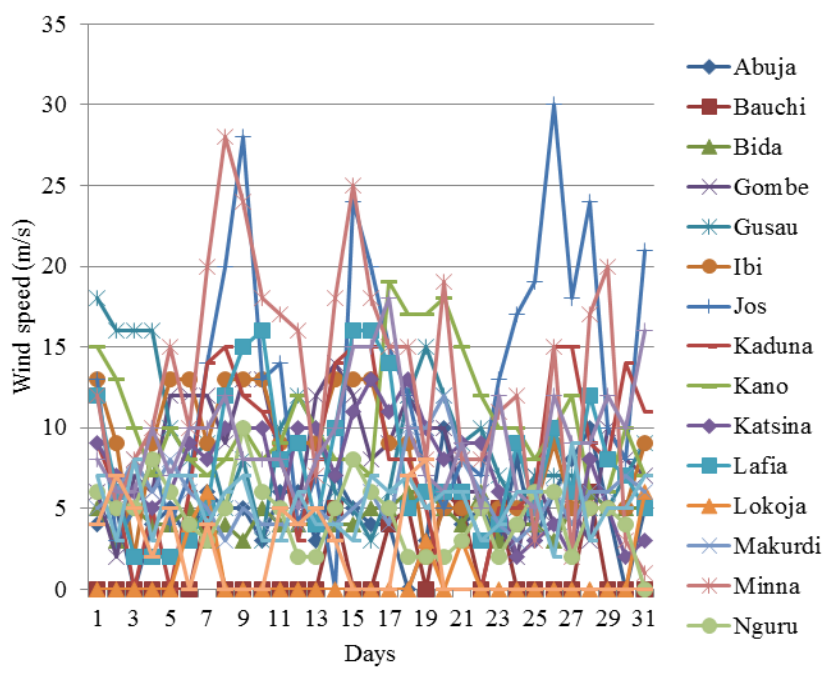

Figure 1: Sites wind speed for the January

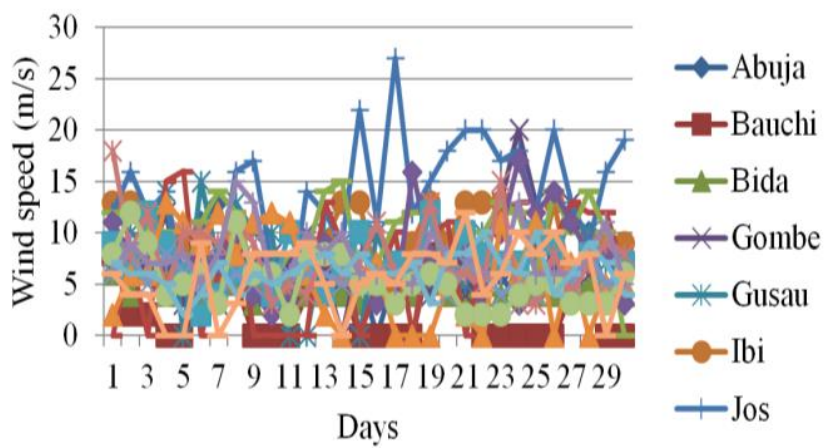

Figure 2: Sites wind speed for the April

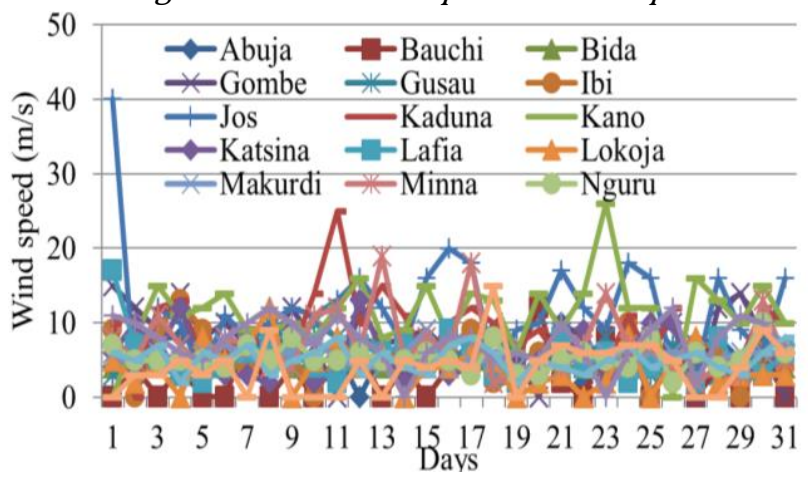

Figure 3: Sites wind speed for the August

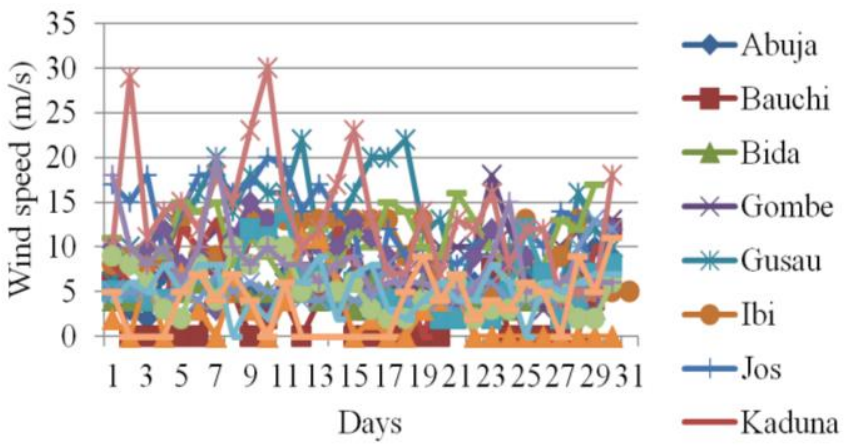

Figure 4: Sites wind speed for the December

\subsection{Estimation of the Average Wind-Power Density}

The average wind-power density can be defined as the annual average power per unit area. In other words, it

Vol. 36, No. 4, October 2017 
can be regarded as the power passing to a site through an area of $1 \mathrm{~m}^{2}$ perpendicular to the wind as defined in Equation (3).

$$
P_{w}=\frac{1}{2} \rho v_{r m c}{ }^{3}
$$

where $P_{w}$ is the average wind-power density at the given site and $\rho$ is the observed air density. The air density is assumed to be constant due to the absence of this from the measured data, and a value of 1.225 $\mathrm{kg} / \mathrm{m}^{3}$ is used. Average wind-power density is given by [16]

$$
\overline{P_{w}}=1 / 2 \rho \sum_{i=1}^{N} P\left(V_{i}\right) * V_{i}^{3}
$$

Equation (4) gives the actual or true power in the wind speed if the probabilities $P(V)$ are determined from the actual wind-speed data. On the other hand, if a probability density function $f(v)$ is used to model the average power in the wind speed, the average power density is given by

$$
\overline{P_{w}}=1 / 2 \rho \int_{0}^{\infty} V^{3} \cdot f(v) \cdot d v
$$

Depending on goodness of fit, if the probability density function fits the actual data, the power predicted by Equations (5) and (3) will be the same. The probability distribution used in the analysis of wind-energy potential includes the Weibull, gamma and Rayleigh distributions [5].

\subsection{Weibull Distributions}

The Weibull distribution is one of the most widely used probability distributions in wind-speed applications. Many research papers, including [17], have defined the Weibull distribution for wind-energy analyses. The mathematical expression of the Weibull distribution is presented in Equation (6) [17] .

$$
f_{w}=\left(\frac{k}{c}\right)\left(\frac{v}{c}\right)^{k-1} e^{\left(-\frac{v}{c}\right)^{k}}
$$

and the cumulative distribution function is

$$
F_{W}=1-e^{\left(-\frac{v}{c}\right)^{k}}
$$

where $c$ is the scale parameter and $k=$ shape parameter.

The probability of the wind speed prevailing at a given site is obtained by the evaluation of $\mathrm{c}$ and $\mathrm{k}$ parameters. Therefore, accurate modelling using the Weibull distribution is based on the accuracy of $c$ and $k$ parameters. Several methods exist for the evaluation of these parameters [18]. One of these methods is the mean-standard deviation. $c$ and $k$ parameters are evaluated using Equations (8) and (9) [18]..

$$
k=\left(\frac{\sigma}{V_{m}}\right)^{-1.086}
$$

$$
c=\frac{V_{m}}{\Gamma\left(1+\frac{1}{k}\right)}
$$

where $\Gamma$ is the gamma function, $\sigma$ is the standard deviation and $V_{m}$ is the mean wind velocity of the sites. The results of Equations (8) and (9) are tabulated in Tables 1 . Once the shape and scale parameters are known, the site average power densities can be obtained using $c$ and $k$ parameters. In this case, the Weibull average wind-power density is obtained using Equation (10) [17].

$$
W P D_{w}=\frac{1}{2} \times \rho \times c^{3} \Gamma\left(1+\frac{3}{k}\right) .
$$

The mean wind speed of the Weibull distribution in terms of $\mathrm{c}$ and $\mathrm{k}$ parameters is expressed in Equation (11)

$$
V_{m}=c \Gamma\left(1+\frac{1}{k}\right)
$$

\subsection{Rayleigh Distribution}

The Rayleigh distribution probability density function is defined in [17]

$$
f(v)=\left(\frac{\pi V}{2 V_{m}}\right) \times e\left(-\frac{\pi}{4}\right) \times\left(\frac{V}{V_{m}}\right)^{2} .
$$

where $V_{m}$ is the mean wind speed, and the cumulative distribution function is given by

$$
F(v)=1-e\left(-\frac{\pi}{4}\left(\frac{V}{V_{m}}\right)^{2}\right)
$$

The variance of this distribution function is obtained using Equation (14)

$$
\sigma^{2}=(4 / \pi-1) \times V_{m}{ }^{2}
$$

Using a similar approach, the average wind-power density is expressed in Equation (15)

$$
W P D=3 / \pi \times \rho \times V_{m}{ }^{3}
$$

Rayleigh distribution is special case of Weibull distribution with a value of $k=2$. Therefore the mean wind speed of this distribution is obtained by

$$
V_{m}=c \sqrt{\frac{\pi}{4}}
$$

Also, the Rayleigh wind-power density is defined as

$$
W P D_{R}=3 / \pi \times \rho \times\left(c \sqrt{\frac{\pi}{4}}\right)^{3}
$$

\subsection{Gamma Distribution}

The gamma probability density function of a data with shape $\alpha$ and scale $\beta$ parameter is defined by

$$
f(x ; \alpha, \beta)=\frac{x^{\alpha-1}}{\beta^{\alpha} \Gamma(\alpha)} e[-x / \beta], \quad x>0, \beta>0
$$

and the cumulative distribution function is defined as

$$
F(x)=\frac{\Gamma(x / \beta) \alpha}{\Gamma(\alpha)} .
$$

where $\Gamma(\mathrm{x})$ is the gamma function. 


\section{Statistical Analysis of Wind Speed For Electrical Power Generation In Some Selected Sites In ... , A. Abdulkarim, et al}

In the same way, the expression for wind-power density for a gamma function in terms of $c$ and $k$ parameter is given by:

$$
W P D_{\text {Gam }}=\frac{1}{2} \rho \times c^{3}[k(k+1)(k+2)]
$$

\subsection{Goodness of Fit}

Several tests exist for predicting the accuracy of the probability density function of the sites. Some of the methods include root mean square error (RMSE) [19], chi-square test $\left(x^{2}\right)$, correlation coefficient $(\mathrm{R})$, and coefficient of determination (COD) [20]. In this section, the performance of the model in predicting the windpower densities of the sites is assessed by the value of percentage errors as follows [21]:

$$
\begin{gathered}
\text { monthly error }(\%)=\frac{P_{x}-P_{A}}{P_{A}} \times 100 \%, \\
x=W, R, G
\end{gathered}
$$

Similarly, the annual mean error of the power density is defined in Equation (22).

$$
\begin{gathered}
\text { annual mean error }(\%)=\frac{1}{12} \sum_{i=1}^{12} \frac{P_{x}-P_{A}}{P_{A}} \times 100 \%, \\
x=W, R, G
\end{gathered}
$$

where $P_{x}$ is the Weibull, Rayleigh and gamma distributions power density and $P_{A}$ is the actual power density of the site determined from the actual wind speed. The comparison is obtained by quantifying the errors evaluated in Equations (21) and (22). The closer the error is to $0 \%$, the more accurate is the model in predicting the wind-power density of the site.

\subsection{Application of the Procedure}

The proposed procedure is tested on data for some sites shown Figure 5. The results of the analyses are presented in Tables 1 . The result presented Weibull, Rayleigh and gamma function fitting parameters for the sites under consideration. In Table 1 , a lower value of $k<2$ shows a greater deviation about the mean wind speed. On the other hand, a higher value of $k>2$ indicates a small variation about the mean wind speed. The annual average power densities and Monthly percentage errors (\%) of the sites are presented in Table 2. The result shows that the average wind-energy density predicted is $489.412,820.235$ and $480 \mathrm{~W} / \mathrm{m}^{2}$ for Weibull, Rayleigh and gamma distributions respectively. Critical observation shows that in all the frequency distributions considered, the wind-energy densities of most sites are different.

In the same way, the annual average errors of windspeed data are $0.10435,0.70871$ and $0.07722 \mathrm{pu}$ for Weibull, Rayleigh and gamma respectively. This shows that the gamma distribution fits best followed by Weibull and Rayleigh distributions in the selected sites. The performance of the individual site shows that the Weibull distribution fits the recorded data better in most cases compared to both Rayleigh and gamma distributions. The whole analysis shows that the Weibull distribution fits best in all the sites, followed by

\begin{tabular}{|c|c|c|c|c|c|c|c|}
\hline \multicolumn{2}{|r|}{ PDF } & \multicolumn{2}{|c|}{ Weibull Dist. } & \multicolumn{2}{|c|}{ Rayleigh Dist. } & \multicolumn{2}{|c|}{ Gamma Dist. } \\
\hline \multirow{2}{*}{ Sites } & \multirow{2}{*}{$\begin{array}{c}\text { Geographical } \\
\text { Location(Long., Lat.) }\end{array}$} & \multicolumn{6}{|c|}{ Parameter } \\
\hline & & $k$ & $c$ & $k$ & $c$ & $k$ & $c$ \\
\hline Abuja & $9^{0} 5^{\prime} \mathrm{N}, 7^{0} 32^{\prime} \mathrm{E}$ & 2.6897 & 6.2820 & 2 & 6.3119 & 6.3727 & 0.9874 \\
\hline Bida & $9^{0} 5^{\prime} \mathrm{N}, 6^{0} 1^{\prime} \mathrm{E}$ & 5.7177 & 4.6225 & 2 & 4.8215 & 25.1773 & 0.1830 \\
\hline Gombe & $10^{0} 17^{\prime} \mathrm{N}, 11^{0} 10^{\prime} \mathrm{E}$ & 2.5222 & 9.0399 & 2 & 9.0738 & 5.6372 & 1.5752 \\
\hline Gusau & $12^{0} 09^{\prime} \mathrm{N}, 6^{0} 40^{\prime} \mathrm{E}$ & 2.6411 & 9.1233 & 2 & 9.1626 & 6.1768 & 1.5386 \\
\hline Ibi & $8^{0} 19^{\prime} \mathrm{N}, 9^{0} 51^{\prime} \mathrm{E}$ & 2.9795 & 8.7252 & 2 & 8.8082 & 8.2765 & 1.3167 \\
\hline Jos & $9^{0} 55^{\prime} \mathrm{N}, 8^{0} 54^{\prime} \mathrm{E}$ & 3.1175 & 14.8710 & 2 & 15.0481 & 8.5111 & 2.0144 \\
\hline Kaduna & $10^{0} 31^{\prime} \mathrm{N}, 7^{0} 26^{\prime} \mathrm{E}$ & 1.5549 & 7.4513 & 2 & 7.7204 & 2.3962 & 3.5757 \\
\hline Kano & $11^{0} 59^{\prime} \mathrm{N}, 8^{0} 31^{\prime} \mathrm{E}$ & 2.9506 & 11.3675 & 2 & 11.4551 & 7.5428 & 1.4877 \\
\hline Katsina & $12^{0} 59^{\prime} \mathrm{N}, 7^{0} 35^{\prime} \mathrm{E}$ & 2.1497 & 7.4536 & 2 & 7.4868 & 4.2579 & 1.7006 \\
\hline Lafia & $8^{0} 29^{\prime} \mathrm{N}, 8^{0} 31^{\prime} \mathrm{E}$ & 2.8148 & 6.2528 & 2 & 6.3022 & 7.0073 & 0.9935 \\
\hline Lokoja & $7^{0} 48^{\prime} \mathrm{N}, 6^{0} 44^{\prime} \mathrm{E}$ & 1.0454 & 3.6520 & 2 & 4.0832 & 1.1572 & 3.5205 \\
\hline Makurdi & $7^{0} 44^{\prime} \mathrm{N}, 8^{0} 32^{\prime} \mathrm{E}$ & 4.8286 & 6.0020 & 2 & 6.1904 & 19.4048 & 0.4129 \\
\hline Minna & $9^{0} 36^{\prime} \mathrm{N}, 6^{0} 33^{\prime} \mathrm{E}$ & 2.1513 & 9.2655 & 2 & 9.2998 & 4.1739 & 2.2241 \\
\hline Nguru & $12^{0} 52^{\prime} \mathrm{N}, 10^{0} 27^{\prime} \mathrm{E}$ & 2.3615 & 5.9476 & 2 & 5.9750 & 5.0640 & 1.2444 \\
\hline Sokoto & $13^{0} 3^{\prime} \mathrm{N}, 5^{0} 13^{\prime} \mathrm{E}$ & 3.0813 & 8.9300 & 2 & 9.0292 & 8.2995 & 1.1865 \\
\hline Yelwa & $10^{0} 17^{\prime} \mathrm{N}, 9^{0} 47 \mathrm{E}$ & 3.0409 & 6.2692 & 2 & 6.3394 & 8.0434 & 0.8331 \\
\hline Yola & $9^{0} 12^{\prime} \mathrm{N}, 12^{0} 29^{\prime} \mathrm{E}$ & 1.4621 & 4.7351 & 2 & 4.9154 & 2.1438 & 2.3529 \\
\hline \multicolumn{2}{|c|}{ Annual Average } & 2.6543 & 7.3143 & 2 & 7.4721 & 7.2300 & 1.7767 \\
\hline
\end{tabular}
gamma distribution on a site basis. In addition it is observed that, wind speed distribution varies with state in northern Nigeria.

Table 1: Scale and shape parameters of different distribution for selected sites 


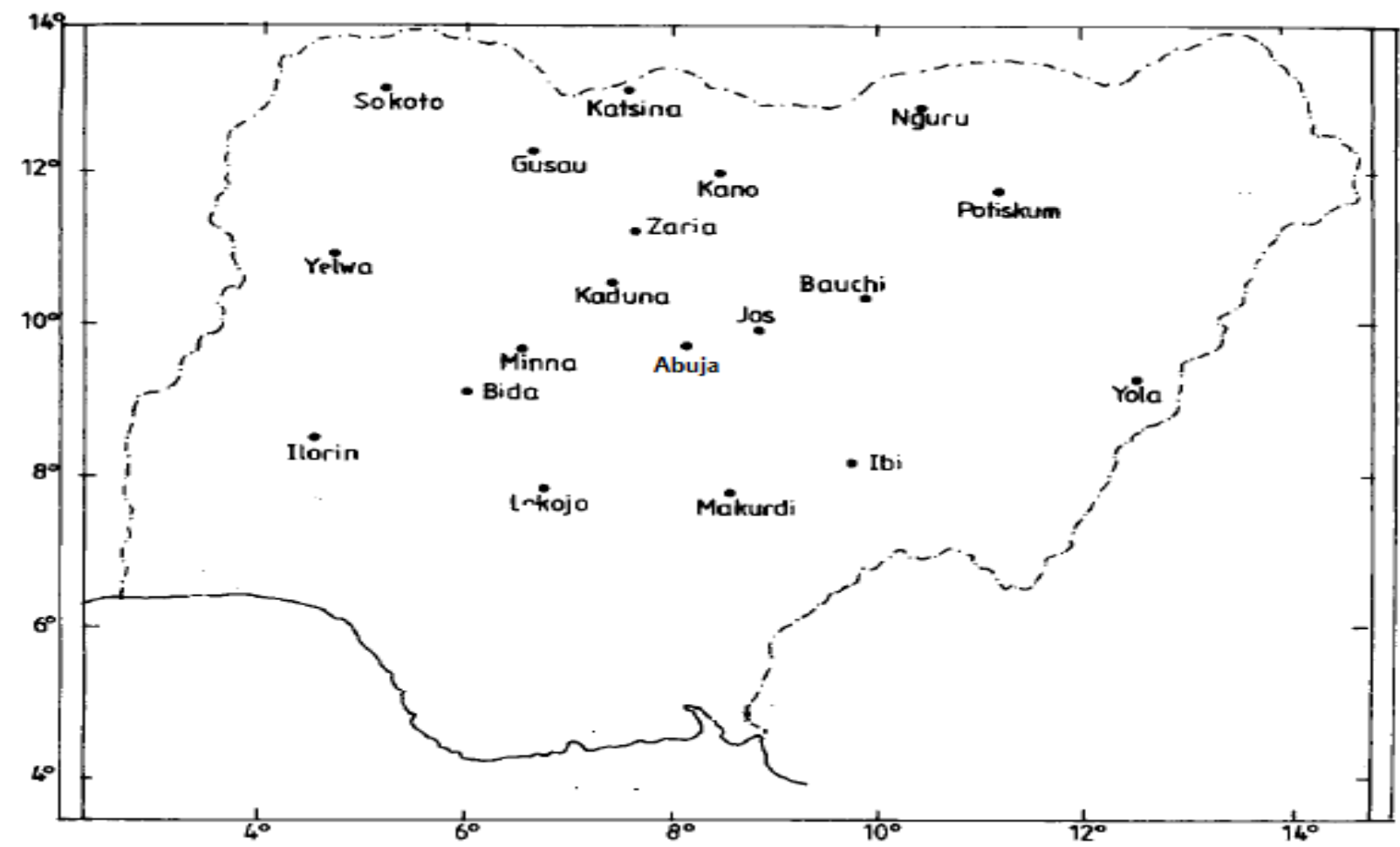

Figure 5: Map of Nigeria showing the sites used in the analysis

Table 2: Annual average wind-power densities and mean error.

\begin{tabular}{|c|c|c|c|c|c|c|}
\hline \multirow{3}{*}{ Sites } & \multicolumn{2}{|c|}{ Weibull Dist. } & \multicolumn{2}{|c|}{ Rayleigh Dist. } & \multicolumn{2}{|c|}{ Gamma Dist. } \\
\hline & & & Paran & & & \\
\hline & WPD $\left(\mathrm{W} / \mathrm{m}^{2}\right)$ & Error (pu) & WPD $\left(\mathrm{W} / \mathrm{m}^{2}\right)$ & Error (pu) & WPD $\left(\mathrm{W} / \mathrm{m}^{2}\right)$ & Error (pu) \\
\hline Abuja & 174 & 0.0298 & 306 & 0.8417 & 179 & 0.0585 \\
\hline Bida & 55 & -0.0014 & 133 & 1.4323 & 55 & 0.0025 \\
\hline Gombe & 538 & 0.022 & 918 & 0.7468 & 554 & 0.0533 \\
\hline Gusau & 666 & 0.0338 & 1132 & 0.8194 & 687 & 0.0632 \\
\hline Ibi & 484 & 0.0299 & 895 & 0.8712 & 496 & 0.0574 \\
\hline Jos & 2147 & 0.0034 & 4013 & 0.9276 & 2198 & 0.025 \\
\hline Kaduna & 616 & 0.1452 & 591 & 0.1233 & 627 & 0.1737 \\
\hline Kano & 948 & 0.0185 & 1799 & 0.9328 & 968 & 0.0413 \\
\hline Katsina & 358 & 0.0132 & 573 & 0.5069 & 371 & 0.0535 \\
\hline Lafia & 194 & -0.0068 & 334 & 0.8124 & 200 & 0.0187 \\
\hline Lokoja & 193 & 1.1891 & 102 & -0.3274 & 181 & 0.3445 \\
\hline Makurdi & 126 & -0.0004 & 280 & 1.269 & 127 & 0.0091 \\
\hline Minna & 855 & -0.0015 & 1233 & 0.5097 & 889 & 0.0366 \\
\hline Nguru & 173 & 0.0282 & 269 & 0.6498 & 180 & 0.0632 \\
\hline Sokoto & 468 & -0.0127 & 888 & 0.9027 & 478 & 0.0083 \\
\hline Yelwa & 161 & 0.0197 & 308 & 0.9431 & 164 & 0.042 \\
\hline Yola & 164 & 0.264 & 170 & 0.0867 & 169 & 0.262 \\
\hline Annual Average & 489.41 & 0.10435 & 820.24 & 0.70871 & 501.35 & 0.07722 \\
\hline
\end{tabular}

Therefore, the assumption of uniform probability distribution could lead to underestimation or overestimation of wind power density of some sites.

\subsection{Effects of $\mathrm{c}$ and $\mathrm{K}$ Parameters on the Probability Distribution Function}

In order to show the effects of $c$ and $k$ parameters on the probability distribution functions, data for the month of January is used. The analysis in section 1.7 has shown that Weibull best fits the wind speed data of the sates. In the same way, Jos has the highest wind energy density compared to other site; the result presented in this section is also sample of the sites. Figure 6 shows a fitting of Weibull distribution in the wind speed data of Jos for a representative month. Therefore, the analysis in this section is based on Weibull distribution function by considering different levels of $c$ and $k$.The results are shown in Figures 7 to 
8. It can be observed that increase in the $k$ level by $25 \%$ and $50 \%$ has a significant effect on the probability distribution shown in figures 7 and 8 by nearly the same factor. In the same way, increase in the $c$ by the same factor is shown in Figures 9 and 10. Sharp decrease in the probability distribution is observed compared to the site wind speed. Therefore, the error of prediction becomes more pronounced compared to the original wind speed data.

\subsection{Wind Power Classification}

According to the European Wind Energy Association (EWEA) classification shown in Table 3, it can be observed that the classes of sites differ. In northern Nigeria, only Bida falls in class 1 and therefore is not suitable for wind-energy development. Abuja, Makurdi, Lafia, Lokoja, Nguru, Yelwa and Yola, are class 2. Those in class 3 include Gombe, Gusau, Ibi, Kaduna, Katsina and Sokoto while Jos, Kano and Minna fall in class 4. Class 2 are usually suitable if tall towers are used, therefore is considered marginal. In addition, Classes 3 and 4 are referred to very good and exceptionally good respectively for wind energy generation [22]. Most of the sites considered are suitable for wind-power generation from off-grid to grid-connected modes.

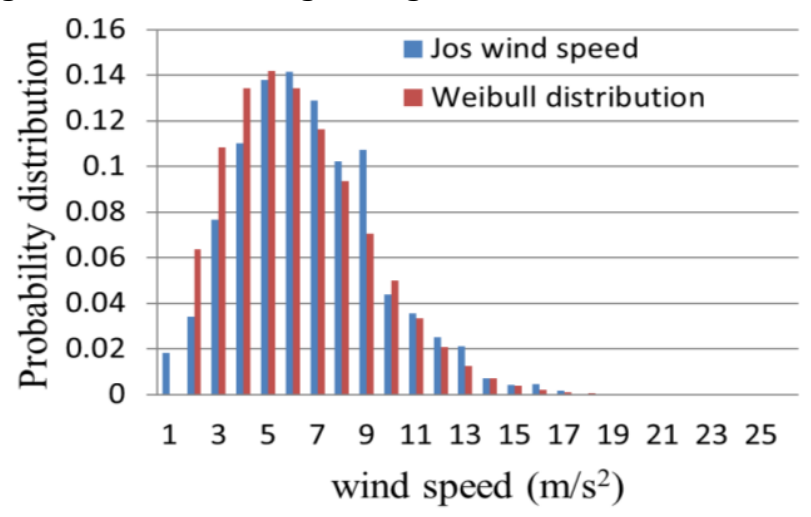

Figure 6: Comparing wind speed and Weibull distribution.

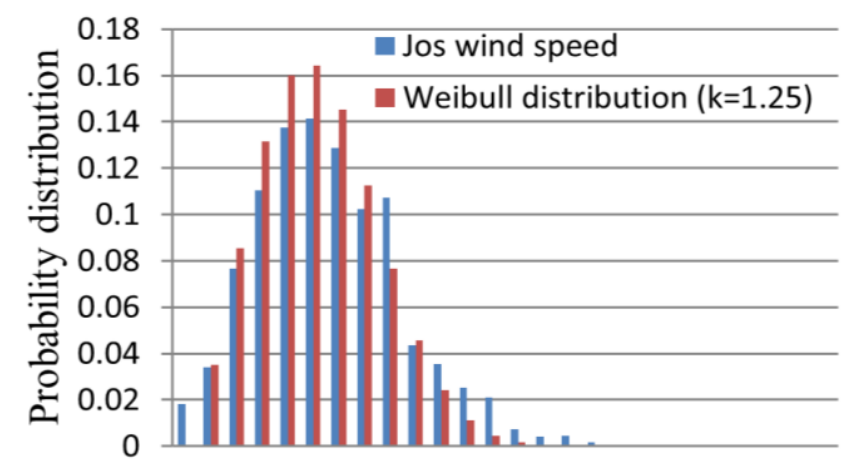

$\begin{array}{lllllllllllll}1 & 3 & 5 & 7 & 9 & 11 & 13 & 15 & 17 & 19 & 21 & 23 & 25\end{array}$

$$
\text { wind speed }\left(\mathrm{m} / \mathrm{s}^{2}\right)
$$

Figure 7: Comparing wind speed and Weibull distribution (25\% increase in $k$ ).

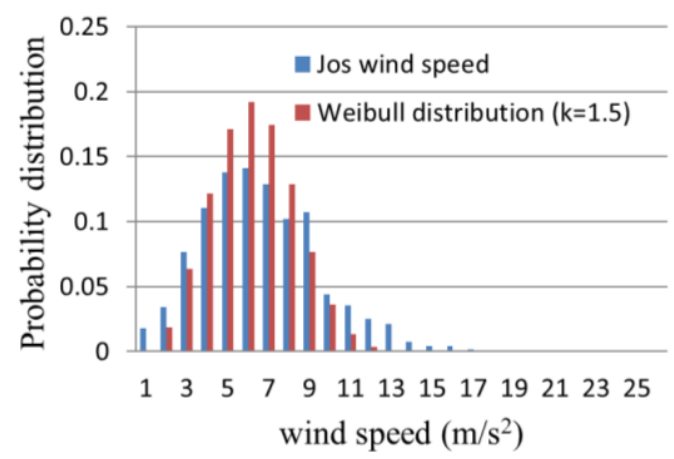

Figure 8: Comparing wind speed and Weibull distribution ( $50 \%$ increase in $k$ ).

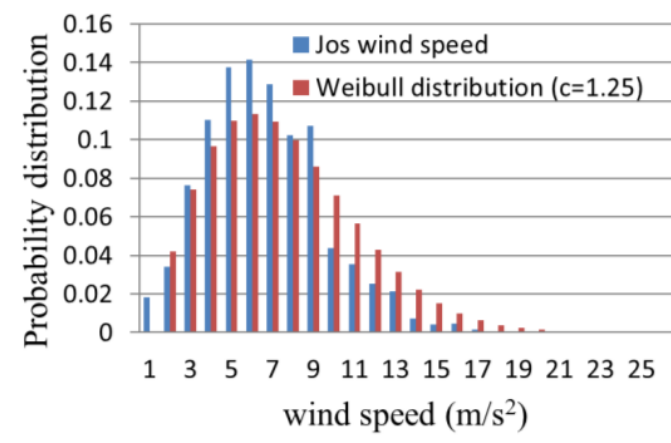

Figure 9: Comparing wind speed and Weibull distribution (25\% increase in c).

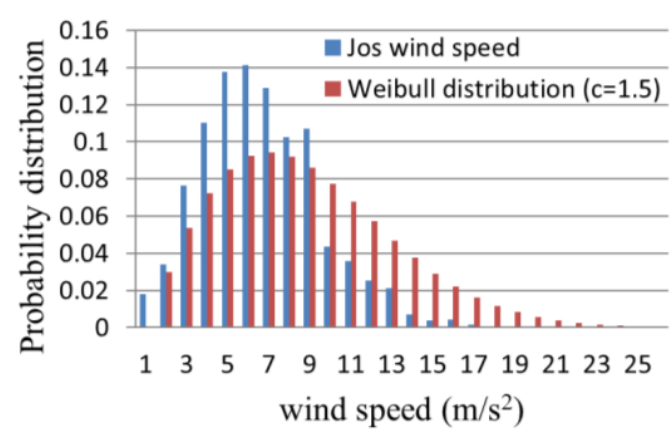

Figure 10: Comparing wind speed and Weibull distribution ( $50 \%$ increase in c).

Table 3: Wind-energy power classification [23]- [24].

\begin{tabular}{lcc}
\hline Category & Power $\left(\mathrm{W} / \mathrm{m}^{2}\right)$ & Class \\
\hline Poor & $\mathrm{P}<100$ & 1 \\
Fairly good & $100 \leq \mathrm{P}<300$ & 2 \\
Good & $300 \leq \mathrm{P}<700$ & 3 \\
Very good & $\mathrm{P} \geq 800$ & 4 \\
\hline
\end{tabular}

\subsection{Maximum and Probable Wind Speed}

In the analysis of wind-speed data, wind speed carrying the maximum energy $\left(\mathrm{V}_{\mathrm{emax}}\right)$ and the most probable wind speed $\left(\mathrm{V}_{\mathrm{mp}}\right)$ are of exclusive interest to the system planner. Wind speed carrying the maximum energy is used to estimate the rated wind speed. On the 


\section{Statistical Analysis of Wind Speed For Electrical Power Generation In Some Selected Sites In ... , A. Abdulkarim, et al}

other hand, the most probable wind speed is the one which represents the peak of the probability density function [25]. Since the Weibull distribution accurately fits the wind-speed data, these two wind speeds are defined in the Equations (23) and (24) for $V_{\text {emax }}$ and $\mathrm{V}_{\mathrm{mp}}$ respectively [26].

$$
\begin{aligned}
& \mathrm{V}_{\mathrm{emax}}=c\left(\frac{k+2}{k}\right)^{\frac{1}{k}} . \\
& \mathrm{V}_{\mathrm{mp}}=c\left(\frac{k-1}{k}\right)^{\frac{1}{k}} .
\end{aligned}
$$

In order to determine these wind speeds, the simulation is carried out for all the sites under consideration. The results are as shown in Figures 11 and 12. It can be seen that Lokoja and Kaduna have the highest maximum energy carrying wind speed and the most probable wind speed.

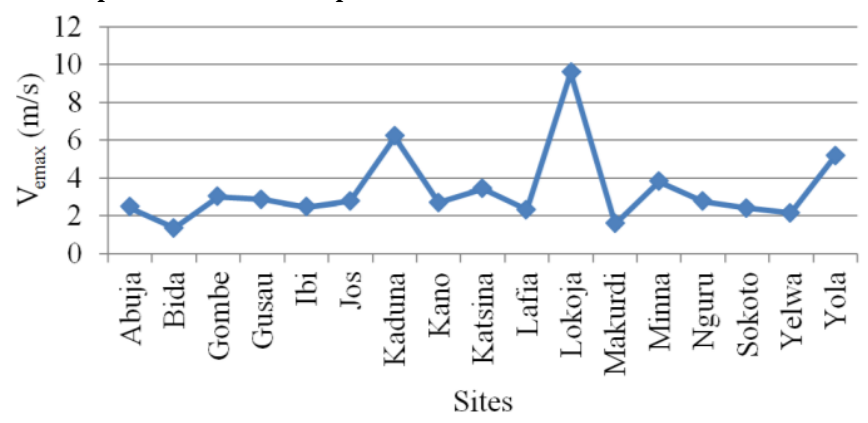

Figure 11: Comparing the maximum energy carrying wind speeds.

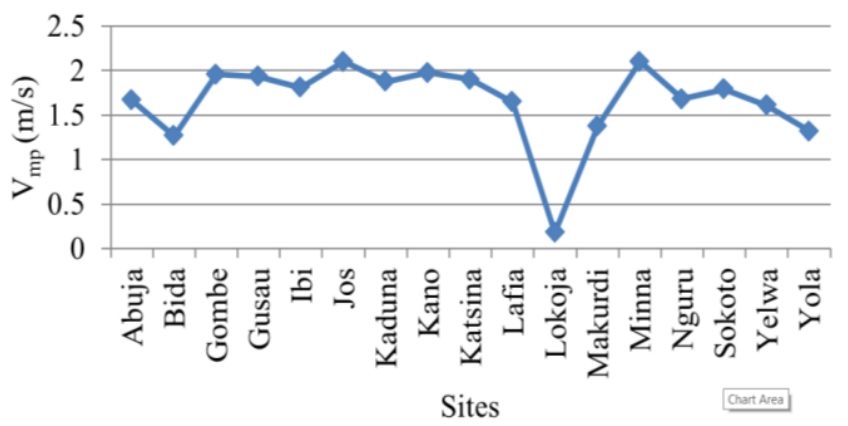

Figure 12: Comparing the most probable wind speeds.

\subsection{Electrical Output Power from a Real Wind Turbine}

Installing a wind turbine in any site is capital intensive; therefore, it is important to match the site parameters with available wind turbine generators. This will make it possible to estimate the electrical power that could be obtained from the available wind turbine models. Many models are available for simulating the electrical power of a wind turbine generator. The magnitude of the power that can be produced by a practical wind turbine generator is simulated using [27].

$$
P_{e}=\left\{\begin{array}{cc}
P_{r} \cdot \frac{V_{i}-V_{c i}}{V_{r}-V_{c i}} & V_{c i}<V<V_{r} \\
P_{R} & V_{r} \leq V<V_{c o} \\
0 & V \leq V_{c i} \text { or } V \geq V_{c o}
\end{array}\right.
$$

where $P_{r}$ is the rated electrical power, $V_{c i}$ is the cut-inspeed, $V_{r}$ is the rated wind speed, $V_{c o}$ is the cut-off wind speed. The capacity factor of each wind turbine generator is obtained by using equation (26). Table 4 shows the technical parameters of the available wind turbine generators [26].

$$
C F=\frac{P_{e a v}}{P_{R}}
$$

where $P_{\text {eav }}=$ average electrical power.

Table 5 shows the system annual output power for different wind turbine generators. Careful examination of the result shows that wind-energy production over the period is in the range of $2241 \mathrm{~kW}$ to $3182 \mathrm{~kW}$ for SWT-3.6-107 wind turbine. In the same vain, the annual averages for all wind turbines used in the simulations are 2877, 2137, 2097, 1137 and $1124 \mathrm{~kW}$ for SWT-3.6-107, V90, AV928, GE1.5sle and GExle respectively. Comparing the GE 1.5 sle and GE 1.5 xle shows that the rated speed is one of the determinant factors that influenced the output power of a practical wind turbine generator. The trend is the same for all the wind turbine generators analysed. This presentation makes it possible to analyse seasonal variations in wind turbine output power. It is clear that the sequence of wind-energy production in each month of the year varies with time and location. Similarly, the sequence in Jos is November, May, September, June, February, December, March, April, October, July, August and January in that order. This means the system output power is sensitive to both location and the seasonal variation. It can be observed that in both locations, AV 928 has the highest capacity factor, followed by GE 1.5 xle, SWT-3-107 AD, GE 1.5 sle and V90 respectively.

Table 4: Turbine technical parameters.

\begin{tabular}{clccccc}
\hline \multirow{2}{*}{ S/No. } & \multirow{2}{*}{ Wind turbine } & $P_{R}(\mathrm{~kW})$ & \multicolumn{3}{c}{ Wind speed $(\mathrm{m} / \mathrm{s})$} & \multicolumn{2}{c}{ Rotor diameter $(\mathrm{m})$} \\
\cline { 4 - 6 } & & & $v_{c i}$ & $v_{R}$ & $v_{c o}$ \\
\hline 1 & GE 1.5 sle & 1500 & 3.5 & 14 & 25 & 77 \\
2 & GE1.5 xle & 1500 & 3.5 & 11.5 & 20 & 82.5 \\
3 & AV 928 & 2500 & 3 & 11.6 & 25 & 93.2 \\
4 & V90 & 3000 & 4 & 15 & 25 & 90 \\
5 & SWT-3.6-107 & 3600 & 3 & 13 & 25 & 107 \\
\hline
\end{tabular}


Statistical Analysis of Wind Speed For Electrical Power Generation In Some Selected Sites In ... , A. Abdulkarim, et al

Table 5: Comparing monthly output power of Jos

\begin{tabular}{lccccc}
\hline Wind turbine & GE 1.5sle & GE 1.5xle & AV 928 & V 90 & SWT-3.6-107 \\
\hline January & 878 & 714 & 1622 & 1636 & 2241 \\
February & 1153 & 1183 & 2155 & 2144 & 2942 \\
March & 1141 & 1125 & 2124 & 2139 & 2903 \\
April & 1136 & 1034 & 2059 & 2155 & 2845 \\
May & 1254 & 1280 & 2297 & 2369 & 3161 \\
June & 1202 & 919 & 2130 & 2309 & 3000 \\
July & 1071 & 1074 & 1960 & 2006 & 2717 \\
August & 1012 & 1095 & 1922 & 1891 & 2590 \\
September & 1243 & 1263 & 2277 & 2336 & 3120 \\
October & 1136 & 1222 & 2132 & 2129 & 2903 \\
November & 1270 & 1349 & 2331 & 2393 & 3182 \\
December & 1151 & 1226 & 2149 & 2140 & 2137 \\
Annual Average & 1137 & 1124 & 2097 & 22 & 2877 \\
\hline
\end{tabular}

Table 6: Different capacity factors for different wind turbines.

\begin{tabular}{lrrrrr}
\hline \multicolumn{1}{c}{ Wind turbine generator } & GE 1.5sle & GE 1.5 xle & AV 928 & V 90 & SWT-3.6-107 \\
\hline January & 0.5714 & 0.4917 & 0.6372 & 0.5303 & 0.6100 \\
February & 0.7863 & 0.7660 & 0.8730 & 0.7366 & 0.8308 \\
March & 0.7158 & 0.7344 & 0.8052 & 0.6676 & 0.7625 \\
April & 0.8187 & 0.7339 & 0.8957 & 0.7771 & 0.8548 \\
May & 0.8525 & 0.7782 & 0.9107 & 0.8182 & 0.8839 \\
June & 0.7098 & 0.6113 & 0.7747 & 0.6676 & 0.7531 \\
July & 0.7158 & 0.7754 & 0.8096 & 0.6648 & 0.7625 \\
August & 0.7515 & 0.7852 & 0.8227 & 0.7131 & 0.7844 \\
September & 0.8095 & 0.8286 & 0.8965 & 0.7625 & 0.8516 \\
October & 0.7573 & 0.8206 & 0.8582 & 0.7038 & 0.8065 \\
November & 0.7576 & 0.7479 & 0.8380 & 0.7121 & 0.7987 \\
December & 0.7143 & 0.9375 & 0.9302 & 0.6364 & 0.8000 \\
\hline Annual Average & 0.7467 & 0.7509 & 0.8376 & 0.6992 & 0.7916 \\
\hline
\end{tabular}

\section{CONCLUSION}

This paper is aimed at comparing different probability distribution function models for fitting the wind-speed data. The probability distribution functions used includes the Weibull, Rayleigh, gamma distributions. The goodness of fit for wind-speed data was judged based on the percentage error between the predicted and the actual power densities. In this paper, the following conclusions can be drawn, as follows:

1. Throughout the study, the Weibull distribution performed best, followed by the gamma, with Rayleigh ranked lowest in predicting the average wind-power densities of selected sites in northern Nigeria.

2. The system output power is sensitive to location, type of wind turbine generator and the seasonal variation.
4 All the sites are suitable for the development of a renewable energy system consisting of wind sources.

5 The capacity factor depends on the location and the seasonal variations in the wind speed of site.

\section{REFERENCES}

[1] A Abdulkarim, S.M Abdelkader, and D. J. Morrow, "Statistical Analyses of Wind and Solar Energy Resources for the Development of Hybrid Microgrid," in 2nd International Congress on Energy Efficiency and Energy Related Materials (ENEFM2014). Switzerland: Springer International Publishing, pp. 9-14, 2015.

[2] S. S Ahmed and H.O Mohammed, "A statistical analysis of wind power density based on the Weibull and Raleigh models of Penjwen region SulaimaniIraq," JJMIE, vol. 6, no. 2, pp. 135-140, 2012. 
[3] A. Zaharim, A. M Razali, R. Z Abidin, and K Sopian, "Fitting of statistical distributions to wind speed data in Malaysia," European Journal of Scientific Research, vol. 26, no. 1, 2009.

[4] M. Vafaeipou, M. H. Valizadeh, O. Rahbari, and M. K. Eshkalag, "Statistical analysis of wind and solar energy potential in Tehran," International journal of renewable energy research, vol. 4, no. 1, pp. 233-239, 2014.

[5] N. C Ali, "A statistical analysis of wind power density based on the Weibull and Rayleigh models at the southern region of Turkey," Renewable Energy, vol. 29, pp. 593-604, 2003.

[6] Abbas Kamran et al., "Statistical analysis of wind speed data in Pakistan," World Applied Sciences Journal, vol. 18, no. 11, pp. 1533-1539, 2012.

[7] A. V Wadagale, P. V Thatkar, Dase R. K., and T. V. Tandale, "Modified Anderson Darling test for wind speed data," International Journal of Computer Science \& Emerging Technologies, vol. 2, no. 2, pp. 249-251, 2011.

[8] L. O. Adekoya and A. A. Adewale, "Wind energy potentila of Nigeria," Renewable energy, vol. 2, no. 1, pp. 33-39, 1992.

[9] M.S Adaranola and O.M. Oyewola, "On wind speed pattern and energy potential in Nigeria," Energy Policy, vol. 19, pp. 2501-2506, 2011.

[10] J. Aidan and J. C. Ododo, "Wind speed distributions and power densities of some cities in northern Nigeria," Journal of engineering and applied sciences, vol. 5, no. 6, pp. 420-426, 2010.

[11] O. S. Ohunakin, M. S. Adaramola, and O. M. Oyewola, "Wind energy evaluation for electricity generation using WECS in Sven selected locations in Nigeria," Applied energy, vol. 88, pp. 3197-3206, 2011.

[12] J.O. Okeniyi, O. S. Ohunakin, and E. T. Okeniyi, "Assessments of Wind-Energy Potential in Selected Sites from Three Geopolitical Zones in Nigeria: Implications for Renewable/Sustainable Rural Electrification," The Scientific World Journal, pp. 1-3, 2015.

[13] G Tina and S Gagliano, "Probability analysis of weather data for energy assessments of hybrid solar/wind power system," in 4th International Conference on Energy, Environment Ecosystems and Sustainable Development, Algarve, pp. 217-223, 2008.

[14] M.R Patel, Wind and solar power system, design, analysis and operations. USA: CRC Press, Taylor Francis, 2006.

[15] Z. O. Olaofe and K. A. Folly, "Evaluation of high wind speed site for large-scale wind energy generation: case study of Slangkop, South Africa.," in Power Engineering Society Conference and Exposition in Africa (Power Africa), IEEE, Johannesburg, 2012.
[16] W. Irshad, K. Goh, and J. Kubie, "Wind resource assessment in the Edinburgh region," in World Nongrid-connected Wind Power and Energy Conference, Nanjing, 2009.

[17] O. Z. Olaope and K. A. Folly, "Statistical analysis of the wind resources at Darling for energy production," International Journal of Renewables Energy Research, vol. 2, pp. 250-261, 2012.

[18] S.A Ahmed, "Comparative study of four methods for Weibull parameters for Halabja, Iraq," International Journal of Physical Sciences, vol. 8, pp. 186-192, 2013.

[19] A Azad, M Golam Rasul, and T. Yusuf, "Statistical diagnosis of the best Weibull methods for wind power assessment for Agricultural Applications," energies, vol. 7, pp. 3056-3085, 2014.

[20] D. K Kidmo, R. Danwe, S. Y. Doka, and Djongyang, "Statistical analysis of wind speed distribution based on six Weibull Methods for wind power evaluation in Garoua, Cameroon," Revue des Energies Renouvelables, vol. 18, no. 1, pp. 105-125, 2015.

[21] J. Liu and Y. Jiang, "A statistical analysis of wind power density based on the Weibull models for Fujian province in China," in World Non-gridconnected Wind Power and Energy Conference, Nanjing, 2009.

[22] J.F Manwell, J. G McGowan, and A. L Rogers, Wind energy explained theory, design and application. United Kingdom: John Wiley and Sons, 2009.

[23] A Mostafaeipour, A. Sedaghat, A. A. Dehghan-Niri, and V. Kalantar, "Wind energy feasibility study for city of Shahrbabak in Iran," Renewable and Sustainable Energy Reviews, vol. 15, pp. 2545-2556, 2011.

[24] A. V. Wadagale, P. V Thatkar, R. K. Dase, and D. V. Tandale, "Modified Anderson Darling Test for Wind Speed Data," International Journal of Computer Science \& Emerging Technologies, vol. 2, no. 2, pp. 249-251, 2011.

[25] S. O. Oyedepo, M. S. Adaramola, and S. S. Paul, "Analysis of wind speed data and wind energy potential in three selected locations in south-east Nigeria," International Journal of Energy and Environmental Engineering, vol. 3, no. 7, pp. 1-11, 2012.

[26] 0. O Ajayi, R. O. Fagbenle, J. Katende, S. A. Aasa, and J. 0 . Okeniyi, "Wind profile characteristics and turbine performance analysis in Kano, north-western Nigeria," International Journal of Energy and Environmental Engineering, vol. 4, no. 27, pp. 1-15, 2013.

[27] A. Abdulkarim, "Optimum design and reliability studies of standalone hybrid renewable energy microgrid," Queens University Belfast, Belfast, PhD thesis 2016. 